Check for updates

Cite this: RSC Adv., 2019, 9, 25318

\title{
Novel vinyl-modified RGD conjugated silica nanoparticles based on photo click chemistry for in vivo prostate cancer targeted fluorescence imaging $\dagger$
}

\author{
Hanrui Li, ${ }^{a}$ Ke Li, ${ }^{b}$ Qi Zeng, ${ }^{a}$ Yun Zeng, ${ }^{a}$ Dan Chen, ${ }^{a}$ Liaojun Pang, ${ }^{a}$ Xueli Chen ${ }^{a}$ \\ and Yonghua Zhan (D) *a
}

\begin{abstract}
Molecular imaging is a powerful tool for non-invasive visualization of tumors that plays an important role in their diagnosis and treatment. The specificity of molecular imaging probes for cancer cells is important for accurate tumor visualization, with antibody and polypeptide nanoprobe conjugates having often been used as targeting agents for tumor detection. However, many traditional chemical conjugation methods employ complex conjugation reactions that result in poor efficiency and poor bioactivity. Herein, we describe the use of photo click methodology for the rapid synthesis of nanoprobes comprised of silica nanoparticles functionalized with RGD targeting units $\left(\mathrm{SiO}_{2} \mathrm{QT} 1-\mathrm{RGDk}\right.$ NPs) $(\sim 80 \mathrm{~nm})$ for in vivo prostate cancer fluorescent imaging applications. These $\mathrm{SiO}_{2} \mathrm{QT} 1-\mathrm{RGDK}$ NPs exhibit a maximum absorption wavelength of $380 \mathrm{~nm}$ in their UV absorption spectra with a maximum fluorescence emission wavelength of $550 \mathrm{~nm}$. Confocal immunofluorescent imaging reveal that $\mathrm{SiO}_{2} \mathrm{OT} 1-\mathrm{RGDk}$ NPs exhibit excellent targeting ability for visualizing cancer cells, with in vivo fluorescence imaging intensity in a subcutaneous tumor model of prostate cancer reaching a maxima after $4 \mathrm{~h}$. Biosafety assessments showed that $\mathrm{SiO}_{2} \mathrm{QT} 1-\mathrm{RGDk}$ NPs demonstrate no obvious toxicity in mice, thus demonstrated that these novel NPs may prove to be promising fluorescent imaging agents for the accurate detection and treatment of tumors.
\end{abstract}

Received 16th June 2019

Accepted 2nd August 2019

DOI: $10.1039 / c 9 r a 04513 a$

rsc.li/rsc-advances

\section{Introduction}

Cancer is a leading cause of death worldwide, with the total number of cancer patients diagnosed globally continuing to grow annually. ${ }^{1}$ Molecular imaging technology is a powerful tool for the non-invasive visualization of tumors, ${ }^{2}$ which can radically affect their diagnosis and treatment. Various imaging techniques are used in clinical research, such as computed tomography (CT), positron emission tomography (PET), magnetic resonance imaging (MRI), single-photon emission computed tomography (SPECT), photoacoustic imaging (PAI) and fluorescence imaging. Amongst these approaches, fluorescence imaging is considered to be one of the most promising methods for early tumor diagnosis and treatment, because it is cost effective, highly sensitive, radiation free, enables rapid imaging and is easy to quantify..$^{3-6}$ This approach requires the

${ }^{a}$ Engineering Research Center of Molecular and Neuro Imaging of the Ministry of Education, School of Life Science and Technology, Xidian University, Xi'an, Shaanxi, 710071, China.E-mail: yhzhan@xidian.edu.cn

${ }^{b}$ Shaanxi Key Laboratory of Ischemic Cardiovascular Disease, Shaanxi Key Laboratory of Brain Disorders, Institute of Basic and Translational Medicine, Xi'an Medical University, Xi'an, Shaanxi, 710021, China

$\dagger$ Electronic supplementary information (ESI) available. See DOI: 10.1039/c9ra04513a availability of high-quality molecular probes for the selective visualization and early diagnosis of tumors in vivo. Selective tumor targeting has often been achieved through conjugation of a molecular imaging nanoprobe to tumor directing antibodies or polypeptides. A range of traditional chemical conjugation methods have been used to prepare these type of imaging probes for in vivo biomedical application, including reductive amination reactions, ${ }^{7,8}$ chemical functionalization of specific groups on the surface of nanoparticles (NPs), ${ }^{9-11}$ and $\mathrm{Cu}(\mathrm{I})-$ catalyzed azide-alkyne cycloaddition reactions. ${ }^{12-14}$ However, these conjugation reactions often require strict temperature control, long-time reactions and employ complex functionalization protocols that can adversely affect the bioactivity of the targeting unit to compromise the probes' cancer cell targeting ability. Consequently, there is a growing demand for the development of efficient and rapid conjugation methods that do not adversely affect the bioactivity of antibody or polypeptide targeting units in fluorescent probes used for tumor diagnosis and treatment.

Photo click chemistry has been reported to provide a fast and efficient conjugation method for the conjugation of antibodies and polypeptides, ${ }^{15-18}$ with the click reaction being initiated via irradiation with light (e.g. no $\mathrm{Cu}(\mathrm{I})$ required). These click reactions involve irradiation of a tetrazole compound with 
ultraviolet light, which results in elimination of nitrogen gas to afford a nitrile imine dipole that can cyclize onto an alkene bond to afford a pyrazoline ring system. ${ }^{\mathbf{1 9 - 2 1}}$ This cycloaddition methodology has the following characteristics: (1) the tetrazole compound only reacts with an olefin in the presence of light which enables it to be used for specific biomolecule labelling applications; (2) the photo click reaction generally exhibits good solvent compatibility, functional group tolerance, stereoselectivity and proceeds in high yield; (3) photochemical initiated decomposition of the tetrazole is rapid, with the rate of formation of the nitrile diamine exhibiting a rate constant of around $0.14 \mathrm{~S}^{-1}$, and the secondary cycloaddition reaction rate of the nitrile diamine with an alkene of around $11.0 \mathrm{M}^{-1} \mathrm{~S}^{-1}$. (4) The pyrazoline cycloaddition product that is formed is fluorescent, so the progress of the cycloaddition reaction employed for its formation can be monitored using fluorescence analysis. Consequently, several research groups have used this type of photo click reaction to functionalize molecular probes for imaging applications. For example, Zhou et al. used this type of photo-click reaction to construct a probe for two-photon imaging of cell apoptosis pathways. ${ }^{22}$ Alternatively, Gai et al. employed photo-click chemistry to prepare a bifunctional chelating-based scaffold for PET/CT multi-modality imaging of U87MG tumor-bearing mice. ${ }^{23}$ However, conjugation of small molecules to polypeptides often results in probes that exhibit short lifecycle in vivo, making it impossible to use them for longterm tumor monitoring.

This study describes the use of photo click chemistry for the preparation of RGD conjugated dense silica nanoparticles ( $\mathrm{SiO}_{2}$ @T1-RGDk NPs) for in vivo molecular imaging of prostate cancer. In our previous study, RGD-modified biodegradable mesoporous silica fluorescent probes were synthesized through photo-click chemistry for in vivo breast cancer imaging. ${ }^{24}$ However, in this study, $\mathrm{SiO}_{2}$ was selected as a nanocarrier instead of mesoporous silica for its good dispersibility and stability, and smaller particle size (within 80 $\mathrm{nm}$ ) compared with mesoporous silica. Moreover, as for the choice of intermediate tetrazole compound, [methyl 4-(2-(4methoxyphenyl)-2H-tetrazol-5-yl) benzoate (T1)] was chose to provide a tetrazole group for photo-click reaction due to its simpler synthesis method, longer UV absorption wavelength, and higher absorbance. Based on previous reports, we have synthesized $\mathrm{SiO}_{2}$ NPs with large surface areas and uniform particle sizes, ${ }^{25-27}$ that are modified with RGD peptides that act as specific targeting ligands for tumor receptors. ${ }^{28-30}$ This has been achieved by first attaching a tetrazole compound $\mathrm{T} 1$ to the surface of amino-modified $\mathrm{SiO}_{2} \mathrm{NPs}\left(\mathrm{SiO}_{2}-\mathrm{NH}_{2} \mathrm{NPs}\right)$. Subsequent photolysis of this T1 modified NP in the presence of a vinyl modified RGD (RGD-Ack) then results in a photoclick reaction to afford the desired fluorescent $\mathrm{SiO}_{2} @ \mathrm{~T} 1-$ RGDk NPs. In vitro cytotoxicity tests have revealed that these monodisperse $\mathrm{SiO}_{2} @ T$ T-RGDk NPs are non-toxic and exhibit excellent targeted cellular uptake levels in tumor cells, where they were found to accumulate in the cytoplasm. These $\mathrm{SiO}_{2} @$ T1-RGDk NPs have been shown to be useful for imaging and detecting tumors in vivo in an established subcutaneous model for prostate cancer in mice.

\section{Experimental}

\section{Reagents}

Tetraethyl orthosilicate (TEOS, 99\%), 1-(3-dimethylaminopropyl)3-ethylcarbodiimide hydrochloride (EDC, crystalline), $N$-hydroxysuccinimide (NHS, 98\%), 3-aminopropyltriethoxysilane (APS) and $p$-anisidine $(\geq 99 \%)$ were purchased from Sigma Aldrich. Ammonia solution $(\geq 25 \%)$, benzenesulfonyl hydrazide (98\%) and sodium nitrite $\left(\mathrm{NaNO}_{2}, 99 \%\right)$ were purchased from Aladdin. Methyl 4-formylbenzoate (99\%) was purchased from J\&K Scientific, whilst pyridine was purchased from Macklin. RGD-Ack was obtained from GL Biochem (Shanghai) Ltd. All reagents and solvents were used as received, without further purification.

\section{Synthesis of $\mathrm{SiO}_{2} \mathrm{NPs}$}

$35.7 \mathrm{~mL}$ of absolute ethanol, $5 \mathrm{~mL}$ of water and $0.785 \mathrm{~mL}$ of ammonia solution were stirred for 10 minutes, $1 \mathrm{~mL}$ of TEOS was then added and the reaction stirred at room temperature for a further $1 \mathrm{~h}$. The desired NPs were then collected by centrifugation and washed with deionized (DI) water and ethanol to remove unreacted TEOS, before then being dispersed in absolute ethanol.

\section{Synthesis of T1}

One equivalent of benzenesulfonyl hydrazide (1.72 g, 10.0 mmol) was added to a stirred solution of methyl 4-formylbenzoate $(1.64 \mathrm{~g}, 10.0 \mathrm{mmol})$ in $100 \mathrm{~mL}$ of dry ethanol and the reaction stirred at room temperature overnight. The resultant white solid precipitate was filtered off to afford a Schiff base that was used directly in the next reaction without further purification. $p$-Methoxyaniline $(615 \mathrm{mg}, 5.0 \mathrm{mmol})$ was dissolved in a mixture of absolute ethanol and water $(1: 1,10 \mathrm{~mL})$, concentrated hydrochloric acid $(1.0 \mathrm{~mL})$ added, and the reaction mixture stirred at $0{ }^{\circ} \mathrm{C}$ for $10 \mathrm{~min}$. An aqueous solution of $\mathrm{NaNO}_{2}(363 \mathrm{mg}, 5.25 \mathrm{mmol})$ in $5 \mathrm{~mL}$ of water was then slowly added over a period of 1 hour at $0{ }^{\circ} \mathrm{C}$. This solution was then added to a solution of the previously prepared Schiff base $(1.59 \mathrm{~g}, 5.0 \mathrm{mmol})$ in $20 \mathrm{~mL}$ of pyridine. After the reaction was complete an equivalent volume of water was added which resulted in precipitation of a large amount of solid that was filtered off and washed with diethyl ether/ethyl acetate $(1: 1)$ to give a pale pink solid.

\section{Synthesis of $\mathrm{SiO}_{2} @ T 1-R G D k$ NPs}

$10 \mathrm{~mL}$ of $\mathrm{SiO}_{2}$ NPs solution $\left(5 \mathrm{mg} \mathrm{mL}{ }^{-1}\right), 10 \mathrm{~mL}$ of absolute ethanol and $1 \mathrm{~mL}$ of APS were mixed together and the resultant reaction mixture was stirred at $88{ }^{\circ} \mathrm{C}$ for $48 \mathrm{~h}$. The resultant $\mathrm{SiO}_{2}-\mathrm{NH}_{2}$ NPs were obtained by centrifugation and washed with absolute ethanol, before being dissolved in DI water. $10.8 \times$ $10^{-6} \mathrm{~mol}$ of $\mathrm{T} 1$ were dispersed in $2 \mathrm{~mL}$ of dimethyl sulphoxide (DMSO), followed by addition of $10.8 \times 10^{-6} \mathrm{~mol}$ of EDC and 5.4 $\times 10^{-5} \mathrm{~mol}$ of NHS. This reaction mixture was stirred for $0.5 \mathrm{~h}$, then $100 \mu \mathrm{L} \mathrm{SiO}{ }_{2}-\mathrm{NH}_{2}$ NPs solution $\left(20 \mathrm{mg} \mathrm{mL}^{-1}\right)$ was added and the reaction mixture was stirred for further $3 \mathrm{~h}$, with any unreacted reagents then being separated off by centrifugation, 
and the precipitate was washed 3 times with DMSO, then the T1 conjugated $\mathrm{SiO}_{2}-\mathrm{NH}_{2}$ NPs $\left(\mathrm{SiO}_{2} @ \mathrm{~T} 1\right.$ NPs) were prepared. $\mathrm{SiO}_{2} @ \mathrm{~T} 1 \mathrm{NPs}$ in $1 \mathrm{~mL}$ of DI water and $1 \mu \mathrm{mol}$ RGD-Ack in $1 \mathrm{~mL}$ of DI water were mixed and placed in a glass vessel that was irradiated at $254 \mathrm{~nm}$ for $2 \mathrm{~h}$ at $0{ }^{\circ} \mathrm{C}$. The resultant $\mathrm{SiO}_{2} @ \mathrm{~T} 1-$ RGDk NPs were then obtained by centrifugation and washed with DI water, before then being dissolved in PBS.

\section{Characterization of NPs}

The morphology and size of the $\mathrm{SiO}_{2}$ NPs were characterized using a JEOL JEM-2100 transmission electron microscope (TEM). The hydrodynamic size and surface zeta potential were measured using a Malvern Zetasizer Nano ZS. Their UV absorption spectra were measured using a UV-visible spectrophotometer. Fluorescent spectra were obtained by a fluorescence spectrometer (F-7000), with fluorescent intensities and regions of interest (ROIs) measured using an IVIS imaging system. The tetrazole compound T1 was characterized using ${ }^{1} \mathrm{H}$ NMR spectroscopy and mass spectrometry (MS). Fourier transform infrared spectroscopy (FTIR) was obtained by infrared spectrometer (Thermo Fisher, Nicolet IS50FT-IR).

\section{Cell lines and animal model}

PC-3 cell lines were provided by Xi'an Medical University and maintained in complete DMEM solution supplemented with $10 \%(\mathrm{w} / \mathrm{w})$ FBS and penicillin-streptomycin (76 and $36 \mathrm{U} \mathrm{mL}^{-1}$, respectively). Cells were incubated under $5 \% \mathrm{CO}_{2}$ at $37{ }^{\circ} \mathrm{C}$ in a cell incubator (MCO-18AIC, Sanyo, Japan), prior to being used for in vitro tests or establishment of mouse model. Nude male mice (4 weeks old, about $18 \mathrm{~g}$ ) were purchased from the Department of Experimental Animals, Health Science Center, Xi'an Jiaotong University. The mice were fed in a SPF animal room whose temperature was maintained at $20^{\circ} \mathrm{C}$, with all mice kept under these conditions for 1 week prior to use. PC-3 luciferase tumor-bearing nude mice model were obtained by inoculating the left and right sides of their crotches with $5 \times 10^{5}$ of the required cells in $20 \mu \mathrm{L}$ of PBS. These mice were then used for in vivo probe distribution experiments after their tumors had grown to an appropriate volume. All animal tests were conducted using protocols approved by the University of Xi'an Jiaotong Animal Care and Use Committee (number XJTULAC 2016-412).

\section{Stability of $\mathrm{SiO}_{2} @ T 1-R G D k$ NPs}

The stability of the $\mathrm{SiO}_{2} @ T 1-R G D k$ NPs was determined by measuring the size distribution of NPs in PBS or 10\% FBS at different temperatures over a period of 5 days, with all data presented as mean values with $\pm \mathrm{SD}(n=3)$.

\section{Cellular uptake and affinity assay}

The cellular uptake of the $\mathrm{SiO}_{2} @ \mathrm{~T} 1-\mathrm{RGDk}$ NPs was measured using a confocal microscope (TCS SP5 II, Leica, Germany). Cells were cultured for $48 \mathrm{~h}$ in confocal dishes containing $\mathrm{SiO}_{2} @ \mathrm{~T} 1-$ RGDk NPs coated onto the glass surfaces of each well. A confocal microscope with laser excitation wavelengths of
$410 \mathrm{~nm}$ was used for detection of $\mathrm{SiO}_{2} @ \mathrm{~T} 1-\mathrm{RGDk}$ NPs. The endocytosis of the $\mathrm{SiO}_{2} @ \mathrm{~T} 1-\mathrm{RGDk}$ NPs was detected by monitoring cellular uptake behavior using a confocal microscope. For confocal microscopy studies, PC-3 cells were incubated with $\mathrm{SiO}_{2} @ \mathrm{~T} 1-\mathrm{RGDk}$ NPs in 6-well plates for a predetermined time, after which time the cells were rinsed with PBS (pH 7.4) and fixed with $4 \%$ paraformaldehyde solution. The effect of RGDAck blocking on PC-3 cells was determined using cellular affinity analysis. PC-3 cells were cultured for $48 \mathrm{~h}$ in 24 -well flatbottomed plates, with the cells in control group were incubated with $\mathrm{SiO}_{2} @ \mathrm{~T} 1-\mathrm{RGDk}$ NPs for $24 \mathrm{~h}$. The cells in blocking group were incubated with RGD-Ack for $24 \mathrm{~h}$ prior to addition of $\mathrm{SiO}_{2} @ \mathrm{~T} 1-\mathrm{RGDk}$ NPs, followed by a further incubation period of $24 \mathrm{~h}$. The fluorescent intensities of PC-3 cells were measured by staining their nuclei using $4^{\prime}$,6-diamidino-2-phenylindole (DAPI), with laser excitation wavelengths of $340 \mathrm{~nm}$ was used for detection.

\section{Cytotoxicity assay}

An MTT method was used to detect the viability of PC-3 cells in the presence of $\mathrm{SiO}_{2} @ \mathrm{~T} 1-\mathrm{RGDk}$ NPs, with cells that had not been exposed to NPs being used as a control. Cells were seeded onto 96-well plates (with a density of $1 \times 10^{5}$ cells per well) and incubated under $5 \% \mathrm{CO}_{2}$ atmosphere at $37{ }^{\circ} \mathrm{C}$. Cells were washed with PBS after $24 \mathrm{~h}$ and the complete medium containing different concentrations of $\mathrm{SiO}_{2} @ \mathrm{~T} 1-\mathrm{RGDk}$ NPs was added to each well. After $72 \mathrm{~h}$, their media was replaced with fresh culture media, before adding $20 \mu \mathrm{L}$ of MTT solution $(5 \mathrm{mg}$ $\mathrm{mL}^{-1}$ ) to each well. These cells were then incubated for further $4 \mathrm{~h}$ under the same conditions, with the media replaced with $100 \mu \mathrm{L}$ of DMSO. The absorbances were measured at $590 \mathrm{~nm}$ using an ELISA plate reader (Infinite ${ }^{\circledR} 200$ Pro, Tecan, Switzerland). The cytotoxicity of $\mathrm{SiO}_{2} @ \mathrm{~T} 1-\mathrm{RGDk}$ NPs was determined using a maximum concentration of $\mathrm{SiO}_{2} @ \mathrm{~T} 1-\mathrm{RGDk}$ NPs of 81 $\mu \mathrm{g} \mathrm{mL}^{-1}$. The in vitro cytotoxicity of $\mathrm{SiO}_{2} @ \mathrm{~T} 1-\mathrm{RGDk}$ NPs, T1, RGD-Ack and $\mathrm{SiO}_{2}$ NPs were measured using the MTT assay described above.

\section{In vivo biotolerance of $\mathrm{SiO}_{2} @ \mathrm{~T} 1-\mathrm{RGDk} \mathrm{NPs}$}

In vivo biotolerance levels of the $\mathrm{SiO}_{2} @ T 1-\mathrm{RGDk}$ NPs were investigated using an acute toxicity method employing twenty male and twenty female BALB/c mice that were divided randomly into two groups with the same sex ratio. These mice were purchased from the Department of Experimental Animals, Health Science Center, Xi'an Jiaotong University and fed under SPF conditions. After 5 days of adaptation, the treatment group were intravenously injected with a dosage of $25 \mathrm{mg} \mathrm{kg}$ $\mathrm{SiO}_{2}$ @T1-RGDk NPs (10 times more than in vivo fluorescence imaging dosage), with the control group injected with saline. Food and water were provided $2 \mathrm{~h}$ after injection and the mortality rate of the mice determined 14 days after injection. Heart, liver and kidney tissues were taken for histopathology analysis. All animal experiments were approved by the Laboratory Animal Administration Committee of Xi'an Medical University and performed according to the Guidelines for Animal Experimentation of Xi'an Medical University and the 
Guide for the Care and Use of Laboratory Animals published by the US National Institutes of Health (NIH publication no. 85-23, revised 1996).

\section{In vivo fluorescence imaging and image analysis}

A subcutaneous transplanted prostate tumor model in nude mice was used for in vivo probe distribution experiments, with mice being divided into three groups: targeted, non-targeted and blocking groups. The tail veins of mice in the targeted and non-targeted groups were injected with $200 \mu \mathrm{L}$ of $\mathrm{SiO}_{2} @ \mathrm{~T} 1-$ RGDk NPs and $\mathrm{SiO}_{2} @ T 1-A M$ NPs (AM: acrylamide), respectively. The blocking group were injected with RGD-Ack $0.5 \mathrm{~h}$ before subsequently being injected with $200 \mu \mathrm{L}$ of $\mathrm{SiO}_{2} @ T 1-R G D k$ NPs. In vivo fluorescence images were obtained at 0, 0.5, 1, 2, 4, 8 and $12 \mathrm{~h}$ after injection with NPs, using a $420 \mathrm{~nm}$ excitation light source and a $570 \mathrm{~nm}$ band-pass emission filter (exposure time of $1 \mathrm{~s}$ ). Injection and image acquisition were carried out on mice that had been anesthetized using isoflurane, with their body temperatures being maintained using a thermostat-controlled thermal heater. Fluorescence images of mice were acquired, with their heart, liver, spleen, lungs, kidneys and tumors then collected and analyzed using an IVIS imaging system. Tissue distribution of $\mathrm{SiO}_{2} @ T 1-R G D k$ NPs in mice was obtained and analyzed using image processing software, with ROIs extracted and visualized using Living Image 4.5 software. Tumor ROIs were determined using white light images, with mean values of fluorescence intensities for each ROI calculated after background values had been subtracted from each fluorescence image. This analysis enabled fluorescence intensity versus time curves of tumor ROIs from these fluorescent images to be determined accurately.

\section{Histology}

Tumors from the three groups of mice were frozen and cryosectioned for histological analysis, with frozen tissue slices of $10 \mu \mathrm{m}$ thickness stained with DAPI and images acquired using a confocal laser scanning microscope (CLSM).

\section{Statistical analysis}

Data are given as mean values $\pm \mathrm{SD}$ of independent repeat experiments, with a $P$-value $<0.05$ considered to represent a statistically significant difference between comparative data.

\section{Results and discussion}

\section{Synthesis and characterization of $\mathrm{SiO}_{2} @ T 1-R G D k$ NPs}

NPs have been widely used for molecular imaging applications, ${ }^{31-33}$ with silica nanoparticles having proven to be one of the most popular nanocarriers used for cancer therapy. ${ }^{27,34-36}$ In this study, $\mathrm{SiO}_{2} @ \mathrm{~T} 1-\mathrm{RGDk}$ NPs were prepared using the protocol described in scheme $1 \mathrm{~A}$, and the reaction between amino-modified $\mathrm{SiO}_{2}$, tetrazole compound and RGD-Ack is shown in the Scheme $\mathrm{S} 1, \dagger$ with $\mathrm{SiO}_{2}$ NPs prepared using a previously reported method. ${ }^{37}$ As shown in Fig. 1A, TEM results reveal that the $\mathrm{SiO}_{2}$ NPs exhibited uniform particle sizes and good monodispersities, with an average diameter of

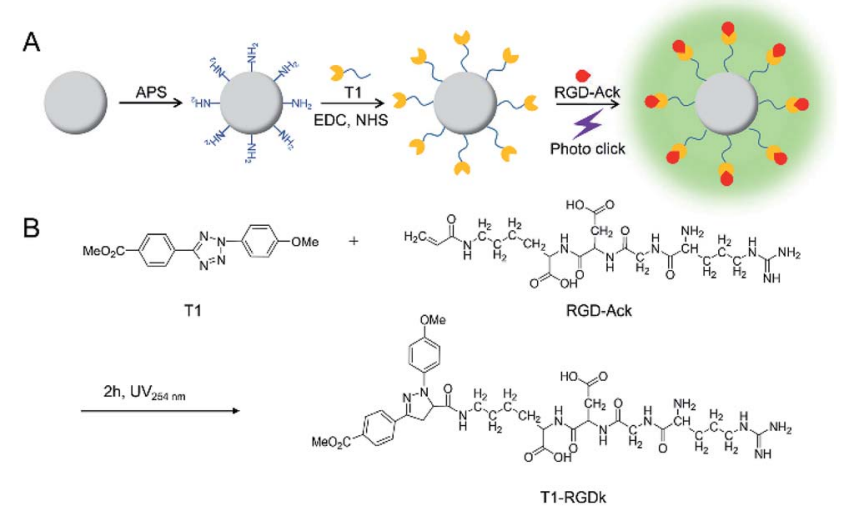

Scheme 1 Synthesis of $\mathrm{SiO}_{2}$ (aT1-RGDk NPs. (A) Synthesis schematic of $\mathrm{SiO}_{2}(\mathrm{aT1}-\mathrm{RGDk} N \mathrm{NP}$; (B) the photo click reaction between tetrazole compound $T 1$ and RGD.

$\sim 80 \mathrm{~nm}$. DLS measurements verified that the $\mathrm{SiO}_{2}$ NPs had an average hydrodynamic diameter of $105.7 \pm 9.6 \mathrm{~nm}$ (Fig. 1B), with particle sizes measured using TEM analysis found to be smaller because of loss of solvent. The $\mathrm{SiO}_{2}$ NPs were functionalized with APS, with the zeta potential of the resultant $\mathrm{SiO}_{2}-\mathrm{NH}_{2}$ NPs found to be $+30.7 \pm 0.57 \mathrm{mV}$ (Fig. S1A $\dagger$ ) indicating that their amino-groups had been successfully modified. The tetrazole compound $\mathrm{T} 1$ was synthesized in high purity according to a previous literature report (Fig. S2 $\dagger$ ), ${ }^{38}$ whose mass spectra and ${ }^{1} \mathrm{H}$ NMR spectra are shown in Fig. S3 and $\mathrm{S} 4, \dagger$ respectively $\left[{ }^{1} \mathrm{H}\right.$ NMR (600 MHz, $d$-DMSO) $\delta=3.87(\mathrm{~s}, 3 \mathrm{H}), 3.91$ $(\mathrm{s}, 3 \mathrm{H}), 7.23(\mathrm{~d}, J=8.1 \mathrm{~Hz}, 2 \mathrm{H}), 8.09(\mathrm{~d}, J=8.1 \mathrm{~Hz}, 2 \mathrm{H}), 8.17(\mathrm{~d}, J$ $=7.6 \mathrm{~Hz}, 2 \mathrm{H}), 8.30(\mathrm{~d}, J=7.6 \mathrm{~Hz}, 2 \mathrm{H})]$. Ultraviolet irradiation of the tetrazole fragment of $\mathrm{T} 1$ results in a reactive nitrile imine dipole that undergoes cycloaddition with the alkene bond of RGD-Ack to generated the fluorescent pyrazoline ring system of T1-RGDk (Scheme 1B). This functionalization method has the advantage of being simple to operate, mild reaction conditions and good efficiency when compared to traditional conjugation methods. T1 was conjugated onto the surface of $\mathrm{SiO}_{2}-\mathrm{NH}_{2} \mathrm{NPs}$

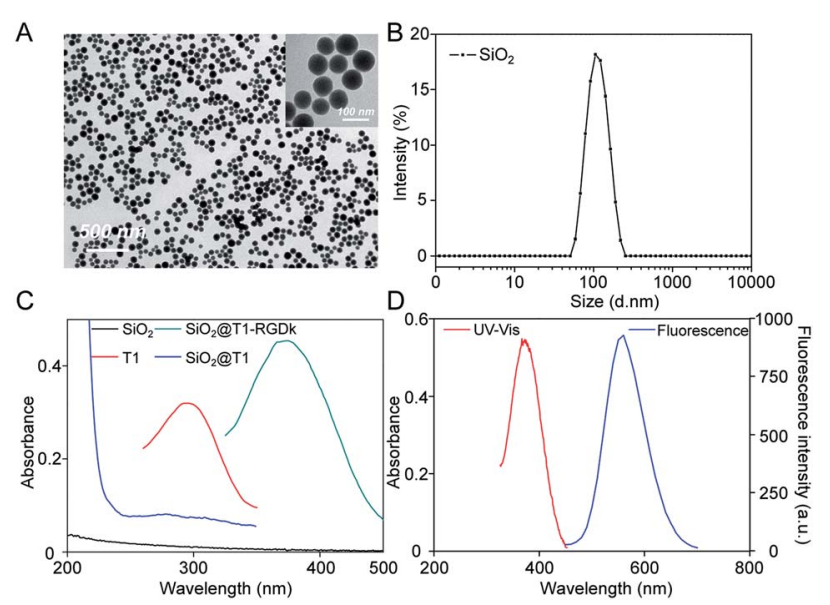

Fig. 1 Characterization of $\mathrm{SiO}_{2}$ (aT1-RGDk NPs. (A) TEM images of $\mathrm{SiO}_{2}$ NPs; (B) size distribution of $\mathrm{SiO}_{2}$ NPs determined through DLS; (C) UV absorption spectra of $\mathrm{T} 1, \mathrm{SiO}_{2} \mathrm{NPs}, \mathrm{SiO}_{2} \mathrm{QT} 1 \mathrm{NPs}$ and $\mathrm{SiO}_{2} \mathrm{QT} 1-\mathrm{RGDK}$ NPs; (D) UV absorption and fluorescence spectra of T1-RGDk. 
using a condensation reaction, with any unreacted $\mathrm{T} 1$ then being separated by ultrafiltration and its concentration was determined. This analysis revealed that around $70 \%$ of the reactive groups of total $\mathrm{T} 1$ input had been successfully conjugated to the surface of the $\mathrm{SiO}_{2}-\mathrm{NH}_{2}$ NPs, with UV and fluorescent analysis confirming that $\mathrm{T} 1$ had been successfully attached to the surface of the NPs. In addition, the zeta potential of $\mathrm{SiO}_{2} @ \mathrm{~T} 1$ changed to $0.006 \mathrm{mV}$ (Fig. S1B $\dagger$ ), which also confirmed that T1 was conjugated on the $\mathrm{SiO}_{2}$ surface successfully. Furthermore, the optimum reaction time of cycloaddition reaction between $\mathrm{T} 1$ and RGD-Ack was confirmed by UV absorption and fluorescence spectra (Fig. S5†). Fig. 1C shows the UV absorption spectra of $\mathrm{SiO}_{2}$ NPs, T1, $\mathrm{SiO}_{2} @ \mathrm{~T} 1 \mathrm{NPs}$ and $\mathrm{SiO}_{2} @ T 1-R G D k$ NPs, with maximum UV absorption wavelengths for $\mathrm{SiO}_{2} @ \mathrm{~T} 1 \mathrm{NPs}$ and $\mathrm{SiO}_{2} @ \mathrm{~T} 1-\mathrm{RGDk}$ NPs observed at 290 and $380 \mathrm{~nm}$, respectively. The UV absorption and fluorescence spectra of T1-RGDk (Fig. 1D) revealed maximum UV absorption and fluorescence emission wavelengths at 380 and $550 \mathrm{~nm}$ respectively, consistent with the presence of their pyrazoline fragments. Furthermore, the successful conjugation of T1 and RGD-Ack was also proved by infrared spectroscopy. As can be seen from Fig. $\mathrm{S} 6, \uparrow$ the carboxyl group $\left(1720 \mathrm{~cm}^{-1}\right)$ on T1 reacted with the amino group on the surface of $\mathrm{SiO}_{2}-\mathrm{NH}_{2}$ $\left(3400 \mathrm{~cm}^{-1}\right)$, and after the photo-click reaction with RGD-Ack, the vinyl group $\left(1650 \mathrm{~cm}^{-1}\right)$ of RGD-Ack disappeared. NP stability is an important factor when carrying out long-term imaging studies in vivo, and so the stability of these $\mathrm{SiO}_{2}$ @T1RGDk NPs was determined by monitoring their size distributions in different solvents at different temperatures over a period of 5 days (Fig. $S 7 \dagger$ ). These results indicated that the particle sizes of $\mathrm{SiO}_{2} @$ T1-RGDk NPs did not change significantly over 5 days, with solutions remaining clear with no evidence of any precipitation having occurred.

\section{Cellular uptake and affinity assay}

The in vitro cellular uptake ability of the model cell line PC-3 towards $\mathrm{SiO}_{2} @$ T1-RGDk NPs was first investigated (Fig. 2A). Confocal microscopy results revealed that the $\mathrm{SiO}_{2} @ T 1-R G D k$ NPs were distributed in the cytoplasm (red), as well as being gathered around the nucleus (blue). These results indicated that $\mathrm{SiO}_{2} @ \mathrm{~T} 1-$ RGDk NPs have good stability in vitro and could be used for in vivo imaging potentially. The affinity assay was used to explore the tumor targeting ability of $\mathrm{SiO}_{2} @ \mathrm{~T} 1-\mathrm{RGDk}$ NPs (Fig. 2B), which showed that the fluorescent intensity of tumor cells exposed to $\mathrm{SiO}_{2} @$ T1-RGDk NPs in the presence of RGD-Ack blocker was significantly reduced. This is consistent with RGD-Ack binding strongly to RGD receptors on the surface of cancer cells to prevent competing binding and internalization of the $\mathrm{SiO}_{2} @ \mathrm{~T} 1-\mathrm{RGDk}$ NPs. Quantitative analysis of cell fluorescent intensities (Fig. S8†) confirmed enhanced uptake of $\mathrm{SiO}_{2} @ T 1-R G D k$ NPs into the cancer cells, thus demonstrating their potential use for selective in vivo tumor targeted imaging applications.

\section{Toxicity assays of $\mathrm{SiO}_{2} @$ T1-RGDk NPs in vitro and in vivo}

The cytotoxicity of $\mathrm{SiO}_{2} @ T 1-R G D k$ NPs, $\mathrm{SiO}_{2}$ NPs, T1, RGD-Ack were evaluated using an MTT assay. Fig. 3 reveals that the

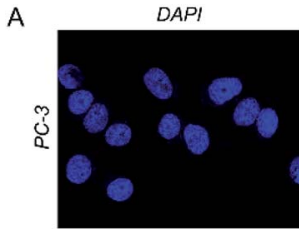

B
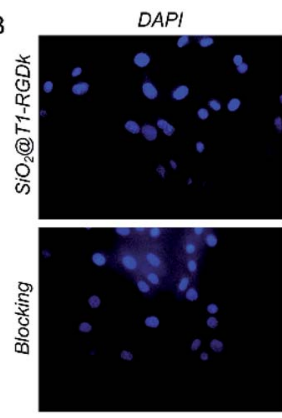

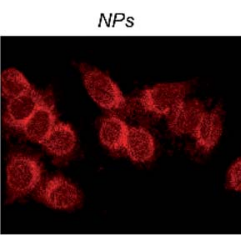

NPS
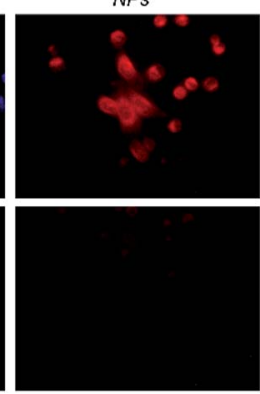

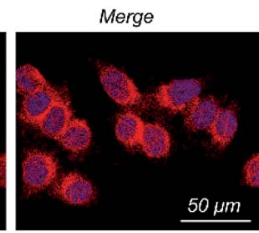

Merge

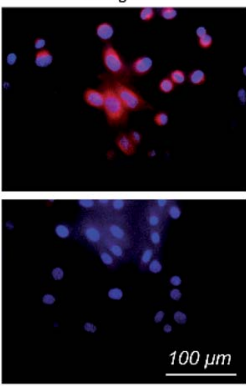

Fig. 2 (A) Confocal immunofluorescent images of $\mathrm{SiO}_{2}$ (aT1-RGDK NPs showing their localization in PC-3 cells. (B) Confocal immunofluorescent images of $\mathrm{SiO}_{2} \mathrm{QT} 1-\mathrm{RGDK}$ NPs showing their localization in PC-3 cells in the presence of RGD-Ack blocking agent. Cells stained with DAPI are colored blue. Cells containing $\mathrm{SiO}_{2} @$ @T1-RGDk NPs are colored red.

$\mathrm{SiO}_{2} @ \mathrm{~T} 1-\mathrm{RGDk}$ NPs exhibited no significant cytotoxicity within a certain concentration range that required for imaging applications $\left(0.001\right.$ to $\left.81 \mu \mathrm{g} \mathrm{mL} \mathrm{m}^{-1}\right)$. The tail veins of healthy BALB/c mice were injected with $\mathrm{SiO}_{2} @ T 1-R G D k$ NPs $\left(25 \mathrm{mg} \mathrm{kg}^{-1}\right)$ and their major organs (heart, liver and kidneys) harvested for histopathological analysis after 2 weeks (Fig. 4). Survival rates after $14 \mathrm{~d}$ were $95 \%$, with no noticeable tissue or cellular damage being observed in the major organs of mice, when compared to control groups. These results suggest that $\mathrm{SiO}_{2} @ T 1-\mathrm{RGDk}$ NPs demonstrate no obvious toxicity in mice and may potentially be used as a safe fluorescent probe for tumor imaging applications.

\section{In vivo fluorescence imaging and biodistribution studies}

In vivo long-term monitoring of tumors is very important for accurate cancer diagnosis and treatment, so it was decided to

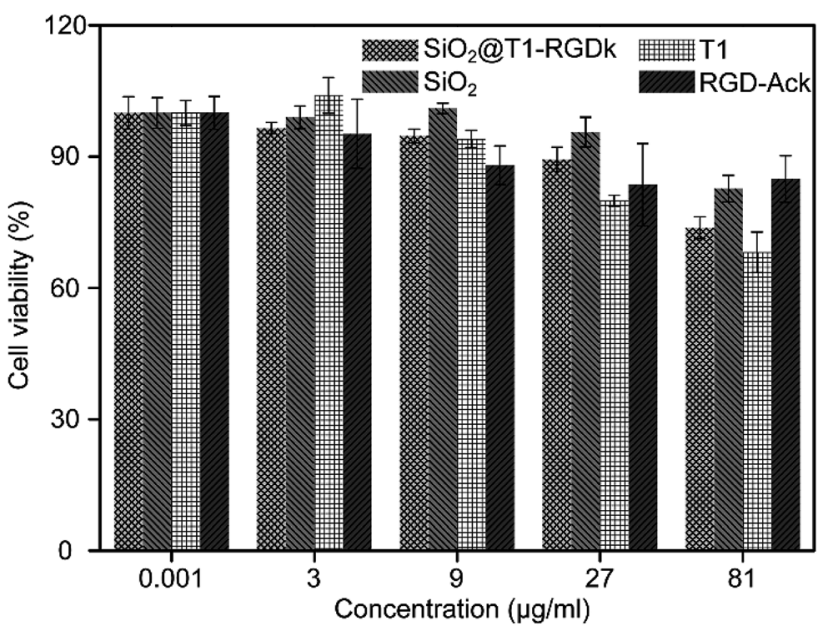

Fig. 3 Cell viability of PC-3 cells incubated with different concentrations of $\mathrm{SiO}_{2} \mathrm{OT} 1-\mathrm{RGDk}$ NPs, $\mathrm{SiO}_{2} \mathrm{NPs}, \mathrm{T} 1$ and RGD-Ack. 


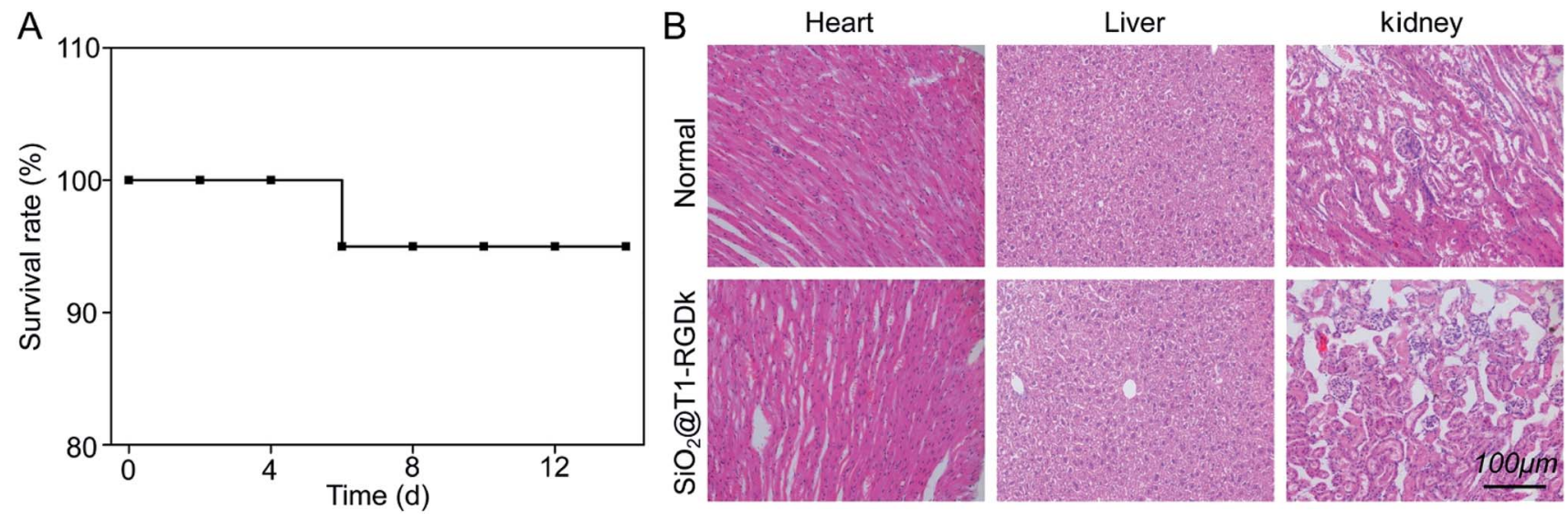

Fig. 4 Acute toxicity results of $\mathrm{SiO}_{2}$ (aT1-RGDk NPs in BALB/c mice; (A) survival rates of $\mathrm{SiO}_{2} \mathrm{QT}$ T1-RGDk NPs in BALB/c mice; (B) H\&E staining of major organs (including heart, liver and kidneys) from mice 14 days after injected with $\mathrm{SiO}_{2}(\mathrm{OT} 1-\mathrm{RGDk} N \mathrm{NP}$. Healthy mice treated with saline were used as control.

determine whether $\mathrm{SiO}_{2} @ \mathrm{~T} 1-\mathrm{RGDk}$ NPs could be used for the targeted imaging of tumors in vivo. A prostate cancer subcutaneous tumor model was chosen for screening, with fluorescent images being obtained using IVIS imaging. Fig. 5 showed the in vivo fluorescence images of three groups of experimental mice within 12 hours. The excitation and emission wavelengths are $420 \mathrm{~nm}$ and $570 \mathrm{~nm}$ in the process of in vivo fluorescence imaging, which inevitably lead to the strong autofluorescence of the skin in this wavelength range, further resulting in weak fluorescence intensity of the tumor sites. In order to accurately show the changes in the fluorescence intensity of the tumor sites, the ROIs of the tumors are extracted. Subcutaneous tumors in the left and right groins of mice were used for analysis (black circle and green circle), which enabled the fluorescence intensities of ROIs to be determined accurately, with tumor ROIs being identified using white light images. The curves of fluorescence intensities of these tumors over a $12 \mathrm{~h}$ period were shown in Fig. 5B, with black square lines and red circle lines describing the fluorescence intensity variations of the left and right tumors for the three groups, respectively. Significant fluorescent intensity enhancement in tumors were observed after probe injection into targeted groups, with the fluorescence intensity of the targeted group reaching a maximal level $4 \mathrm{~h}$ after injection. The fluorescence intensity of the nontargeted group displayed a small increase when compared to the targeted group, which is due to passive accumulation of $\mathrm{SiO}_{2} @$ @T1-RGDk NPs caused by the EPR effect of cells. For the blocking group, in vivo fluorescence imaging was performed by
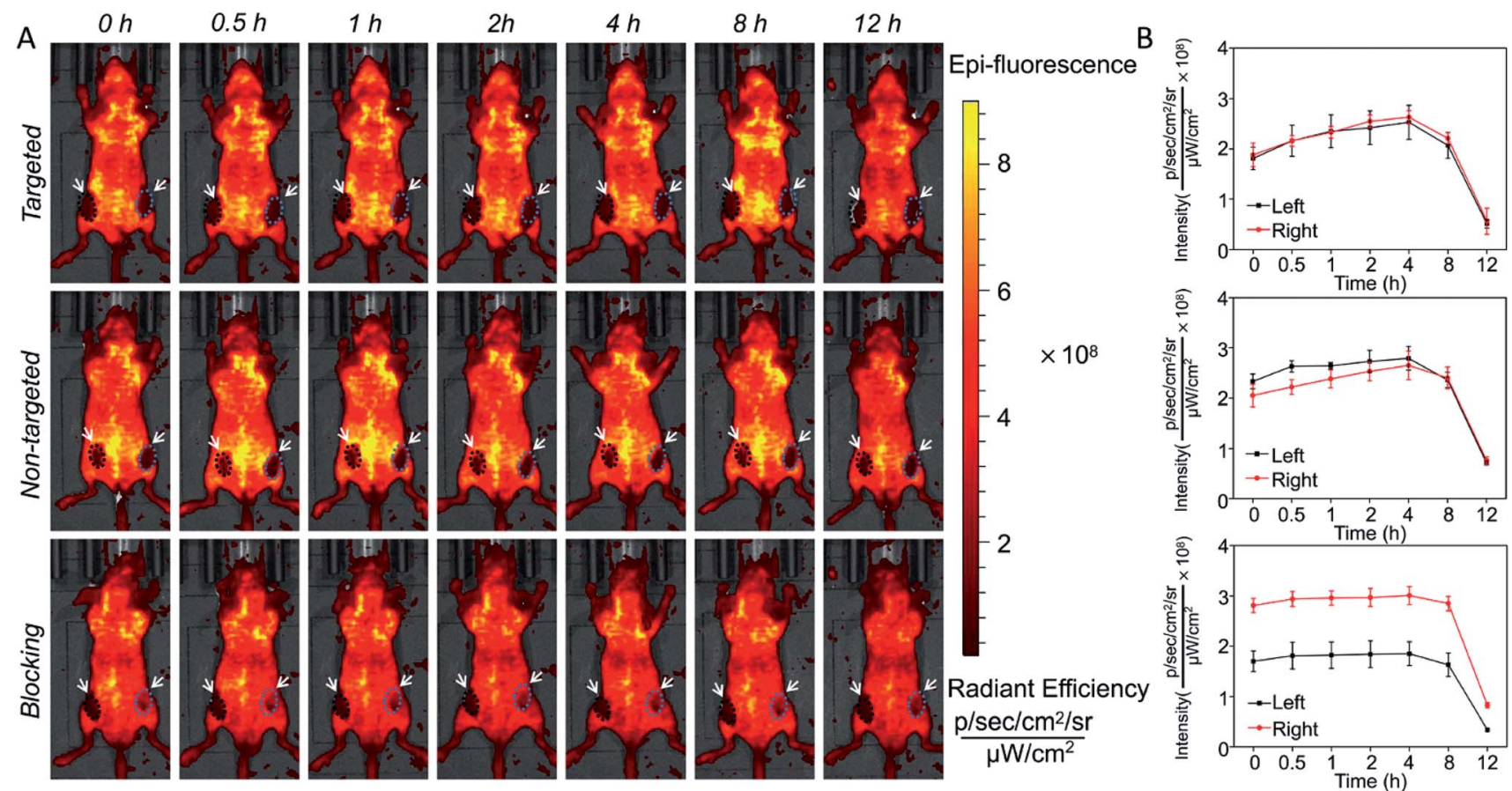

Fig. 5 (A) In vivo fluorescent imaging of $\mathrm{SiO}_{2} \mathrm{Q}$ T1-RGDk NPs after 12 h. (B) Changes in fluorescent intensity of $\mathrm{SiO}_{2}$ @T1-RGDk NPs that occur during in vivo imaging studies over time. 

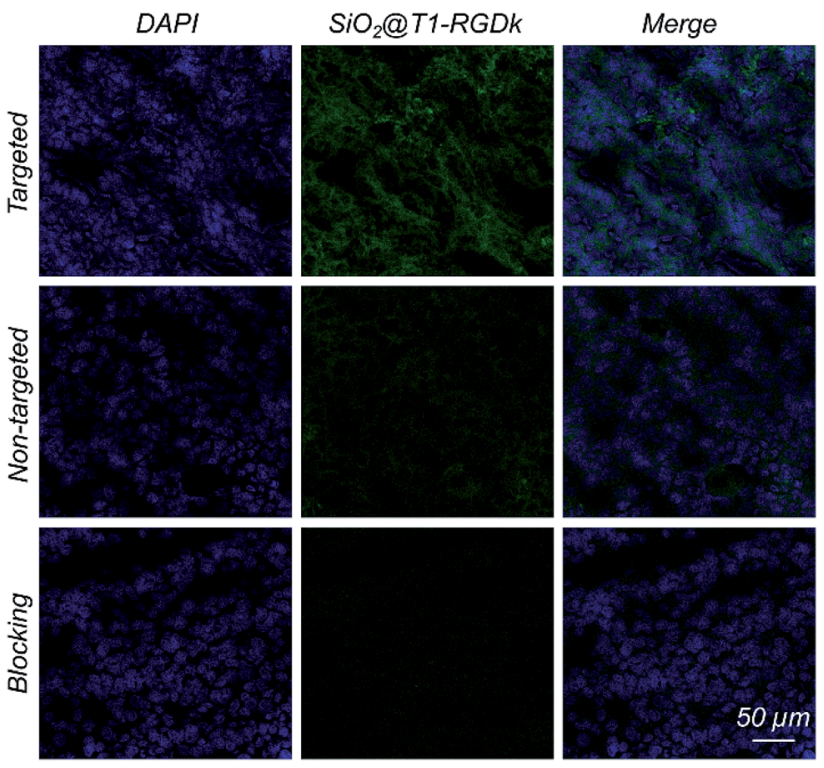

Fig. 6 Fluorescent images of frozen tumor cross-sections, shown by good superposition of blue and green fluorescence signals that correspond to DAPI and dSiO ${ }_{2}$ aT1-RGDk NPs, respectively.

injecting RGD-Ack in advance and $\mathrm{SiO}_{2} @ \mathrm{~T} 1-\mathrm{RGDk}$ was injected half an hour later. RGD-Ack is able to occupy the antigenic epitopes on the surface of tumor cells, rendering the $\mathrm{SiO}_{2} @ \mathrm{~T} 1$ RGDk NPs unable to bind to the tumor surface antigens, thereby exhibiting a weaker fluorescent signal. Therefore, the results indicated that the $\mathrm{SiO}_{2} @ \mathrm{~T} 1-\mathrm{RGDk}$ NPs exhibit excellent targeting ability for tumor cells in vivo. These in vivo imaging results were verified by sacrificing the mice of all three groups which enabled their major organs (heart, liver, spleen, lungs, and kidneys) to be removed for fluorescent analysis (Fig. S9A $\dagger$ ). Fig. S9B $\uparrow$ reveals a strong fluorescent intensity for tumors that were exposed to targeted group, with their intensities significantly greater than for non-targeted group, and in the presence of the RGD-Ack blocking group. The ex vivo results further demonstrated the great targeting ability of the $\mathrm{SiO}_{2} @ \mathrm{~T} 1-\mathrm{RGDk}$ NPs for tumor cells.

\section{Histology}

Histological studies were conducted to certify that the RGD-Ack fragment of $\mathrm{SiO}_{2} @ \mathrm{~T} 1-\mathrm{RGDk}$ NPs were responsible for tumor targeting. Fluorescent images of tumors were obtained using CLSM (Fig. 6), which revealed that $\mathrm{SiO}_{2} @ \mathrm{~T} 1-\mathrm{RGDk}$ NPs were mainly distributed throughout the cytoplasm of tumor cells as indicated by good superposition of the blue and green fluorescence signals, which correspond to the presence of DAPI and $\mathrm{SiO}_{2} @ \mathrm{~T} 1-\mathrm{RGDk}$ NPs, respectively.

\section{Conclusions}

In summary, photo click methodology has been used to prepare stable $\mathrm{SiO}_{2} @ \mathrm{~T} 1-\mathrm{RGDk}$ NPs as a fluorescent tumor imaging agent that exhibits low toxicity and good tumor targeting ability. Fluorescence imaging studies in mice reveal that these $\mathrm{SiO}_{2}$ @T1-RGDk NPs exhibit excellent cancer cell targeting ability which results in their accumulation at tumor sites. Their NP character was found to protect their RGD-Ack fragment from degradation in vivo, which resulted in lengthy circulation times. These results suggest that these $\mathrm{SiO}_{2}$ @T1-RGDk NPs are highly promising fluorescence imaging agents for carrying out targeted tumor imaging studies for precise diagnosis and treatment. The excitation and emission wavelengths of these $\mathrm{SiO}_{2} @ \mathrm{~T} 1-\mathrm{RGDk}$ NPs are 410 and $550 \mathrm{~nm}$, respectively, which means that the background in vivo fluorescence imaging is relatively high, which can result in relatively poor contrast levels between tumors and the epidermis. Therefore, we are currently exploring the use of longer-wavelength nanoprobes for the fluorescent imaging of tumors that afford higher levels of resolution, the properties and performance of which will be reported in due course.

\section{Conflicts of interest}

There are no conflicts to declare.

\section{Acknowledgements}

This work was supported, in part, by the National Key R\&D Program of China under Grant No. 2018YFC0910602, the National Natural Science Foundation of China under Grant No. 81627807, 11727813, 81571725, 91859109, 81871397, 81701853, 81660505, the Fok Ying-Tong Education Foundation of China under Grant 161104, the Program for the Young Top-notch Talent of Shaanxi Province, the Research Fund for Young Star of Science and Technology in Shaanxi Province under Grant No. 2018KJXX-018, the Natural Science Basic Research Plan in Shaanxi Province of China under Grant No. 2018JM7072, 2019JQ-519, 2019JQ-045, and the Fundamental Research Funds for the Central Universities (JB181203, JB191201).

\section{References}

1 L. A. Torre, F. Bray, R. L. Siegel, J. Ferlay, J. Lortet-Tieulent and A. Jemal, Ca-Cancer J. Clin., 2015, 65, 87-108.

2 R. Weissleder and M. J. Pittet, Nature, 2008, 452, 580-589.

3 H. Li, K. Li, Y. Dai, X. Xu, X. Cao, Q. Zeng, H. He, L. Pang, J. Liang, X. Chen and Y. Zhan, Nanomed. Nanotechnol. Biol. Med., 2018, 14, 1867-1877.

4 E. A. Owens, M. Henary, G. El Fakhri and H. S. Choi, Acc. Chem. Res., 2016, 49, 1731-1740.

5 Y. Miyata, T. Ishizawa, M. Kamiya, S. Yamashita, K. Hasegawa, A. Ushiku, J. Shibahara, M. Fukayama, Y. Urano and N. Kokudo, Sci. Rep., 2017, 7, 1-10.

6 Y. Dai, J. Yin, Y. Huang, X. Chen, G. Wang, Y. Liu, X. Zhang, Y. Nie, K. Wu and J. Liang, Biomed. Opt. Express, 2016, 7, 1149-1159.

7 B. Bahmani, Y. Guerrero, D. Bacon, V. Kundra, V. I. Vullev and B. Anvari, Lasers Surg. Med., 2014, 46, 582-592.

8 A. van der Ende, T. Croce, S. Hamilton, V. Sathiyakumar and E. Harth, Soft Matter, 2009, 5, 1417-1425.

9 W. Cai, X. Zhang, Y. Wu and X. Chen, J. Nucl. Med., 2006, 47, 1172-1180. 
10 Z. Y. Li, J. J. Hu, Q. Xu, S. Chen, H. Z. Jia, Y. X. Sun, R. X. Zhuo and X. Z. Zhang, J. Mater. Chem. B, 2015, 3, 39-44.

11 Q. Lei, W. X. Qiu, J. J. Hu, P. X. Cao, C. H. Zhu, H. Cheng and X. Z. Zhang, Small, 2016, 12, 4286-4298.

12 J. E. Hein and V. V. Fokin, Chem. Soc. Rev., 2010, 39, 13021315.

13 V. D. Bock, H. Hiemstra and J. H. van Maarseveen, Eur. J. Org. Chem., 2006, 1, 51-68.

14 S. G. Agalave, S. R. Maujan and V. S. Pore, Chem. Asian J., 2011, 6, 2696-2718.

15 E. Lallana, F. Fernandez-Trillo, A. Sousa-Herves, R. Riguera and E. Fernandez-Megia, Pharm. Res., 2012, 29, 902-921.

16 Z. Guo, L. Liang, J. J. Liang, Y. F. Ma, X. Y. Yang, D. M. Ren, Y. S. Chen and J. Y. Zheng, J. Nanoparticle Res., 2008, 10, 1077-1083.

17 P. Wu and V. V. Fokin, Aldrichim Acta, 2007, 40, 7-17.

18 M. van Dijk, D. T. S. Rijkers, R. M. J. Liskamp, C. F. van Nostrum and W. E. Hennink, Bioconjugate Chem., 2009, 20, 2001-2016.

19 Y. Wang, C. I. R. Vera and Q. Lin, Org. Lett., 2007, 9, 41554158.

20 Y. Wang, W. J. Hu, W. Song, R. K. V. Lint and Q. Lin, Org. Lett., 2008, 10, 3725-3728.

21 Z. Li, L. Qian, L. Li, J. C. Bernhammer, H. V. Huynh, J.-S. Lee and S. Q. Yao, Angew. Chem., Int. Ed., 2016, 55, 2002-2006.

22 M. Zhou, J. Hu, M. M. Zheng, Q. H. Song, J. B. Li and Y. Zhang, Chem. Commun., 2016, 52, 2342-2345.

23 Y. Gai, G. Xiang, X. Ma, W. Hui, Q. Ouyang, L. Sun, J. Ding, J. Sheng and D. Zeng, Bioconjugate Chem., 2016, 27, 515-520.
24 X. Y. Xu, H. R. Li, K. Li, Q. Zeng, Y. Liu, Y. Zeng, D. Chen, J. M. Liang, X. L. Chen and Y. H. Zhan, J. Nanomed. Nanotechnol., 2019, 19, 136-144.

$25 \mathrm{X} . \mathrm{Wu}, \mathrm{M} . \mathrm{Wu}$ and J. X. Zhao, Nanomed. Nanotechnol. Biol. Med., 2014, 10, 297-312.

26 A. Liberman, N. Mendez, W. C. Trogler and A. C. Kummel, Surf. Sci. Rep., 2014, 69, 132-158.

27 M.-H. Chan and H.-M. Lin, Biomaterials, 2015, 46, 149-158.

28 L. Kong, C. S. Alves, W. Hou, J. Qiu, H. Moehwald, H. Tomas and X. Shi, ACS Appl. Mater. Interfaces, 2015, 7, 4833-4843.

29 H. Gao, Y. Xiong, S. Zhang, Z. Yang, S. Cao and X. Jiang, Mol. Pharm., 2014, 11, 1042-1052.

30 Q. Chen, H. Wang, H. Liu, S. Wen, C. Peng, M. Shen, G. Zhang and X. Shi, Anal. Chem., 2015, 87, 3949-3956.

31 P. Padmanabhan, A. Kumar, S. Kumar, R. K. Chaudhary and B. Gulyas, Acta Biomater., 2016, 41, 1-16.

32 S. Wilhelm, A. J. Tavares, Q. Dai, S. Ohta, J. Audet, H. F. Dvorak and W. C. W. Chan, Nat. Rev. Mater., 2016, 1, 1-12.

33 G. Chen, I. Roy, C. Yang and P. N. Prasad, Chem. Rev., 2016, 116, 2826-2885.

34 F. Tang, L. Li and D. Chen, Adv. Mater., 2012, 24, 1504-1534. 35 Q. He and J. Shi, Adv. Mater., 2014, 26, 391-411.

36 W.-H. Chen, G.-F. Luo, Q. Lei, F.-Y. Cao, J.-X. Fan, W.-X. Qiu, H.-Z. Jia, S. Hong, F. Fang, X. Zeng, R.-X. Zhuo and X.-Z. Zhang, Biomaterials, 2016, 76, 87-101.

37 F. Chen, H. Hong, S. Shi, S. Goel, H. F. Valdovinos, R. Hernandez, C. P. Theuer, T. E. Barnhart and W. Cai, Sci. Rep., 2014, 4, 1-10.

38 S. Ito, Y. Tanaka, A. Kakehi and K. I. Kondo, Bull. Chem. Soc. Jpn., 1976, 49, 1920-1923. 